\title{
Sensitivity of Esophageal Scintigraphy (Milk Scans) in Detecting Gastro-Esophageal Reflux
}

\author{
Saeed Bafaraj, Awad Alzahrani \\ Department of Diagnostic Radiology, Faculty of Applied Medical Science, King Abdulaziz University, \\ Jeddah, Saudi Arabia \\ Email: smbafaraj@kau.edu.sa
}

Received 4 February 2015; accepted 20 February 2015; published 27 February 2015

Copyright (C) 2015 by authors and Scientific Research Publishing Inc.

This work is licensed under the Creative Commons Attribution International License (CC BY). http://creativecommons.org/licenses/by/4.0/

C. (†) Open Access

\begin{abstract}
Gastro-esophageal scintigraphy (milk scan) is an accurate technique for detecting gastro-esophageal reflux that can be performed rapidly with minimal patient discomfort. A retrospective study was performed to find out to how much radionuclide milk scan is sensitive for detecting gastroesophageal reflux (GER) for 89 patients who subjected to milk scan within Years 2010 to 2013. The study group age is ranging from one month old to four years old. Milk scan was performed using PHILIPS and SEIMENS machine. Tc 99-m sulfur colloid with milk administrated orally or through nasogastric tube to the patient. The highest frequency for milk scan study was in age group of 0 - 6 months old with 77\% positive finding. Patients who suffer repeated vomiting represented the highest reason of examination for milk scan ( $46 \%$ of overall cases), while chocking attacks, pulmonary aspiration, and congenital heart disease, were $26 \%, 16 \%, 12 \%$ respectively of the overall cases. Seventy-nine percent of patients who prepared to be examine using nasogastric tube found with positive finding, $50 \%$ of GER patients have abnormal tracer activity in the mid of esophagus; on the other hand, $50 \%$ of GER patients divided equally between the lower and upper esophagus. The study show that infants especially in age of $0-6$ months old and with repeated vomiting symptoms are strongly recommended to milk scan study rather than fluoroscopy to avoid unnecessary dose to the patients.
\end{abstract}

\section{Keywords}

Gastro-Esophageal Scintigraphy, Milk Scan, Gastro-Esophageal Reflux

\section{Introduction}

Nuclear medicine is the scientific and clinical application of unsealed radiopharmaceuticals for diagnostic, the- 
rapeutic and investigative purposes. By combining a suitable radionuclide with a pharmaceutical, we are able to monitor the behavior of the pharmaceutical by measuring the distribution of the radioactivity. In vivo function studies measure the function of a given organ based upon the concentration, dilution, absorption or excretion of a radiopharmaceutical. They do not require an image of the distribution of the radiopharmaceutical but an accurate measurement of the activity present within an organ or body fluid sample.

\section{Background}

Gastro-esophageal scintigraphy (milk scan) is an accurate technique for detecting gastro-esophageal reflux that can be performed rapidly with minimal patient inconvenience. Milk scan is done to establish the presence of gastro-esophageal reflux which may cause chemical pneumonitis, bacterial pneumonia or mechanical obstruction of the airway. Symptomatic reflux of gastric contents into the esophagus is a very common GI disorder and heartburn is the most common clinical symptom. Complications include esophagitis, bleeding, perforation, and stricture.

The clinical presentation in infants and children differs considerably from that in adults. Besides regurgitation, common symptoms are respiratory problems, iron deficiency anemia, and failure to thrive [1].

\section{Research Plan}

\subsection{Study Subjects}

The study group includes infant ( 0 - 12 months old) and toddlers (13 - 46 months old) boys and girls at nuclear medicine department. Only patients who clinical status required feedings via a nasogastric tube or without nasogastric tube included.

\subsection{Study Design}

Retrospective study analyzes the data of pediatrics records regarding milk scan done in the mentioned hospitals

\subsection{Sample Size}

89 infant and toddlers’ milk scan record were collected.

\subsection{Sampling Techniques}

Data of milk scan record will be collected for infant (0 - 12 months old) and toddlers (13 - 46 months old) boys and girls.

\subsection{Objectives}

To find out how much radionuclide "milk" scan is sensitive for detecting gastro-esophageal reflux.

\subsection{Materials and Method}

A retrospective study was performed for 89 patients who subjected to milk scan within Years 2010 to 2013. The study group age is ranging from one month old to four years old. Milk scan was performed using PHILIPS and SEIMENS machine. Tc 99-m sulfur colloid with milk administrated orally or through nasogastric tube to the patient.

\subsection{Patient Preparation}

- Patient should be fasting overnight or at least 3 hours after liquid meal.

- Barium studies should not be obtained within $48 \mathrm{~h}$ before scintigraphy.

- Nasogastric tube will be inserted prior to the study by a radiology nurse. The tube is inserted through the nose and ends in the stomach.

- The liquid will be injected through the tube for the exam.

- $30 \mathrm{~mL}$ of milk. 
- The total volume should equal that of $1 / 2$ usual feeding for the patient.

- Child supine on the imaging table.

\section{Gastro-Esophageal Reflux Scintigraphy for Reporting}

99mTc-sulfur colloid is the radiopharmaceutical of selected for the study because it is not absorbed from pulmonary mucosa or the gastrointestinal and residue stable in the acidic medium of the stomach. Such absorption would raise the background activity and lower the sensitivity of the study for detection of reflux and aspiration. Computer display permits interactive manipulation of the window likewise as count truncation. These measures enhance the detectability of subtle reflux episodes .Cinematic playback of the on record frames is also useful in detecting reflux and can easily identify patient motion that occurred during the study. Interpretation can be enhanced by produce time activity curves from regions of interest (ROIs) placed above the esophagus. Reflux episodes are seen as sharp spikes. By placed one ROI above the entire esophagus and a second ROI above the upper esophagus and oropharynx, the proportion of severe reflux episodes from the total number of episodes can be determined. Patient movement during the study can introduce significant artifacts in the curves because movement can cause the esophageal region to overlap gastric activity, simulating the appearance of reflux. Images always are inspected for movement prior to interpretation, and motion correction applied when indicated.

\section{Gastro-Esophageal Reflux Imaging Detected by Milk Scan}

A small amount of reflux occurs in infants as a normal physiologic event and resolves spontaneously by 7 to 8 months of age. Clinically important reflux is often evident by 2 months of age. The majorities have a benign course and are symptom free by 18 months of age. However, approximately one third will have persistent symptoms until age 4 and sometimes develop significant squeal, including strictures and even death due to inanition or recurrent pneumonia (5\% - 10\%).

Esophageal clearance is a critical factor in determining whether reflux becomes clinically evident since this determines the duration of mucosal exposure to reflux-ate. Other contributing factors include the efficiency of the anti-reflux mechanism, the volume of gastric contents, the potency of refluxed material (acid, pepsin), mucosal resistance to injury and mucosal reparative ability. Although LES pressure is reduced in many patients with reflux, considerable overlap exists between healthy and ill subjects. Reflux events result due to a transient LES relaxation is not associated with swallowing, or stress reflux due to transient increases in intra-abdominal pressure, or across an atonic sphincter as free reflux. Although most patients with moderate to severe esophagitis have a sliding hiatus hernia, the majority of individuals with a hiatus hernia do not have reflux disease [1].

\section{Data Analysis and Results}

\subsection{Frequency of Gender among the Patient Undergoing Milk Scan Study}

Fifty seven percent infants ( 0 - 12 months old) and toddlers (13 - 46 months old) boys, and $43 \%$ girls infants and toddlers ( 0 - 12 months old \& 13 - 46 months old), participated in this study to estimate and find out how much radionuclide "milk" scans is safe and sensitive in the detection of GERD. Figure 1 shows the frequency distribution of gender in the study.

\subsection{Frequency of Gender in Relation with Milk Scan Study Finding}

Figure 2 shows that regarding the gender in relation with scan study finding, we found that 27 girls out of 37 were positive exam finding, while the negative finding were 10 girls out of 37 and that represent $72 \%$ of the subject group were positive and $28 \%$ were negative for girls group.

For boys group the scan finding were 36 out of 52 were positive, and 16 out of 52 were negative, which mean $69 \%$ of the subject group were positive finding, and $21 \%$ were negative of the overall subject group.

\subsection{Frequency Milk Scan Study Finding in Relation to Age Group}

Figure 3 shows that the age group of 0 - 6 months old represents the highest frequency for milk scan study with $77 \%$ positive finding, while the request for the scan decreases with the increase of age finding for age group 7 12 M, 13 - 18 M, 19 - 24 M, 25 - 46 M. 


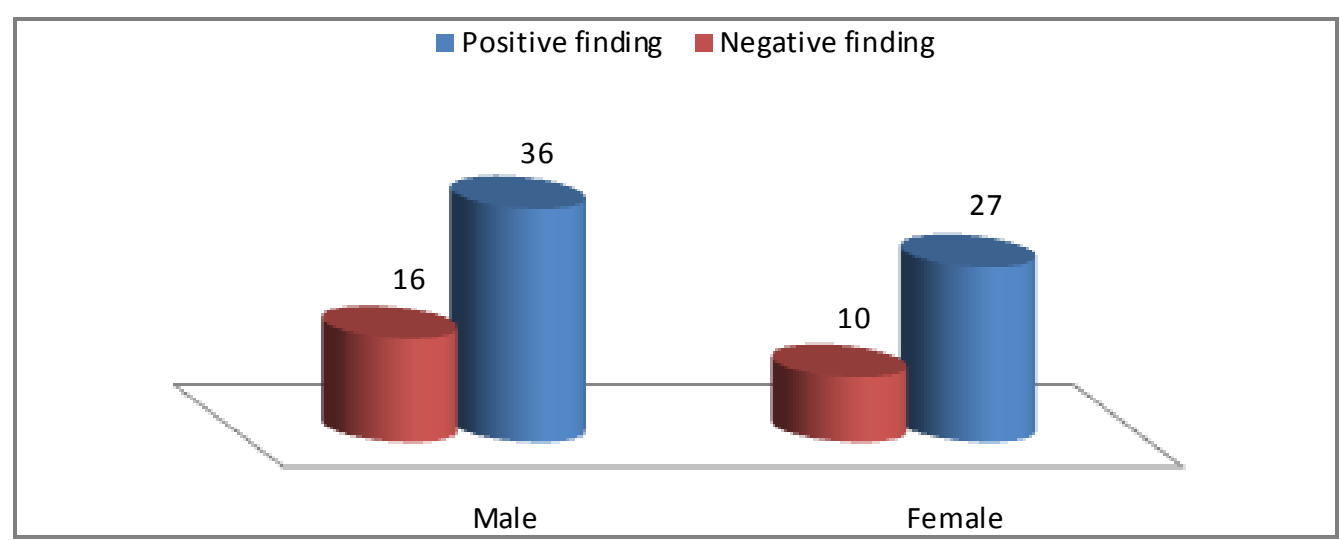

Figure 1. Shows frequency of gender in relation with milk scan study finding.

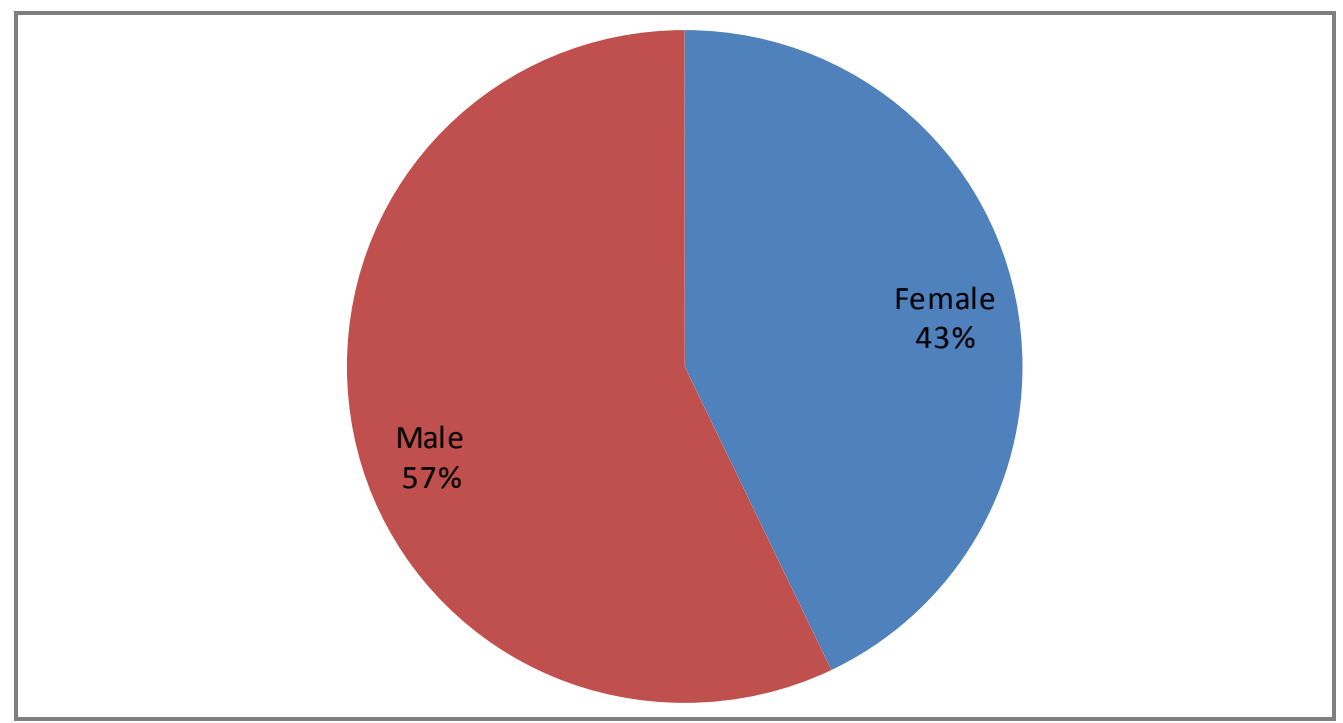

Figure 2. Shows percentage of Positive finding.

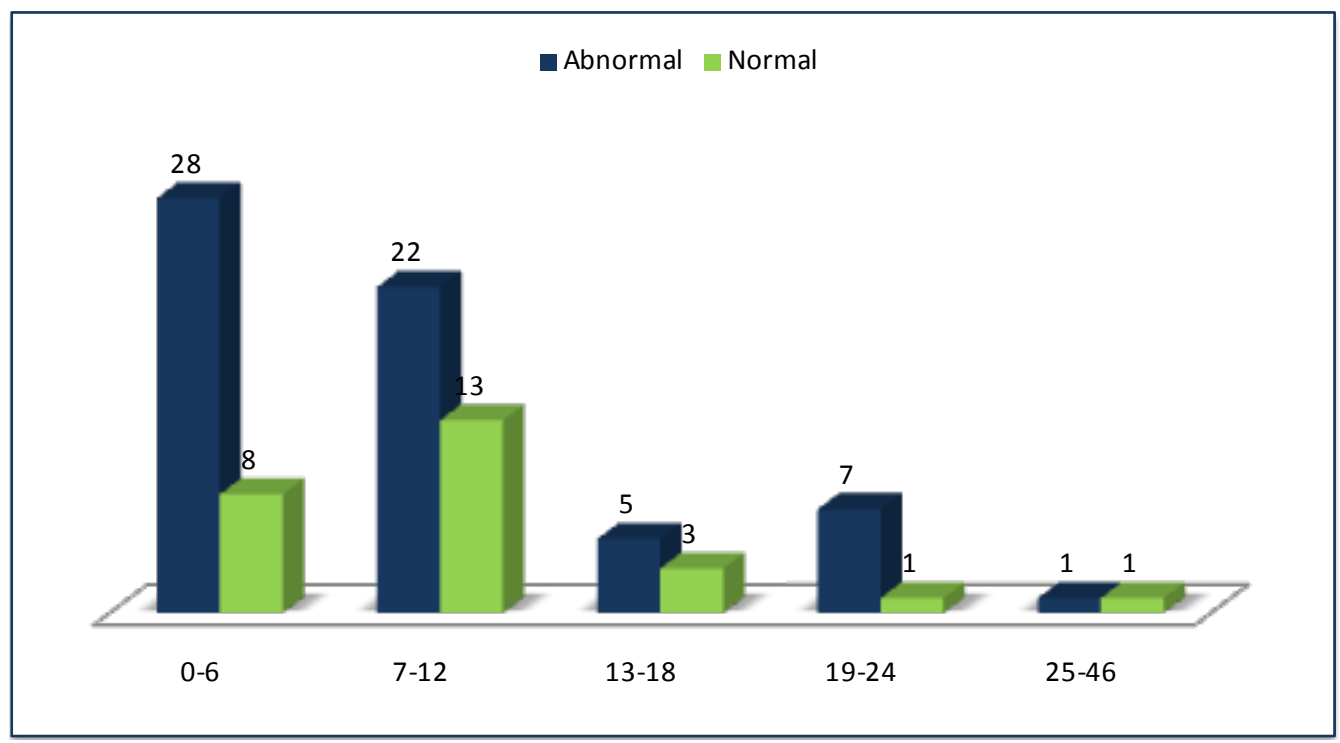

Figure 3. Shows frequency of milk scan study finding in relation to age group. 


\subsection{Frequency Distribution of Clinical Reasons of Examination According to GER Finding}

In regard of GER incidence (Figure 4) according to repeated vomiting, pulmonary aspiration, choking attacks, and CHD symptoms, the studies shows that Repeated vomiting is the highest frequency reason for milk scan study with $46 \%$ of the overall cases, while CHD represents the lowest percent with $12 \%$, although the positive finding of GER were 51\% for repeated vomiting, 57\% for pulmonary aspiration, 52\% for choking attacks, and $81 \%$ for CHD.

\subsection{Frequency Distribution of Reason of Examination in Relation with Milk Scans Study and Finding}

According to Figure 5, the most reason of examination for milk scan was linked with patient who suffering repeated vomiting and that represent $46 \%$ of overall cases, while chocking attacks, pulmonary aspiration, CHD, were $26 \%, 16 \%, 12 \%$ respectively of the overall cases, so repeated vomiting represents the most frequent reason of examination for milk scan study, while CHD represents the lowest reason of examination for milk exam study.

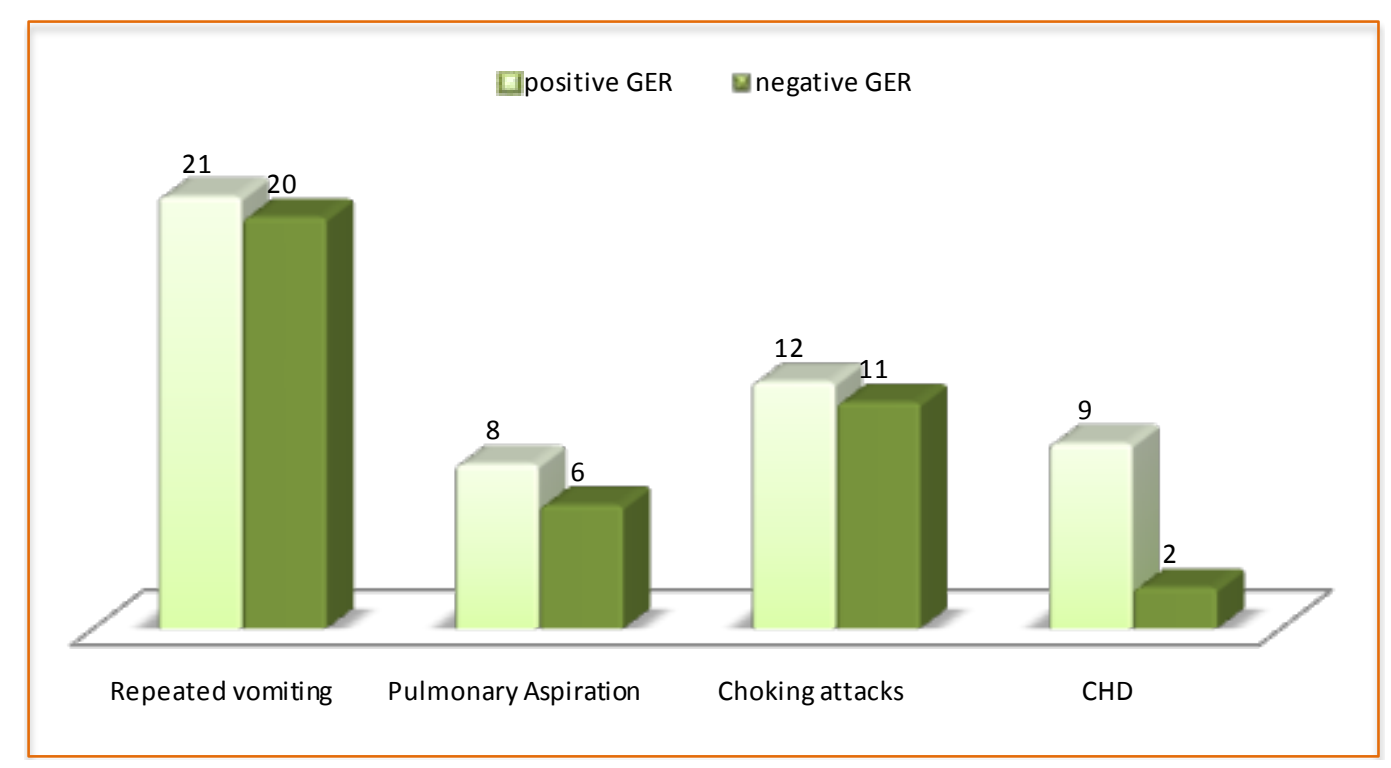

Figure 4. Shows frequency distribution of clinical reasons of examination according to GER finding.

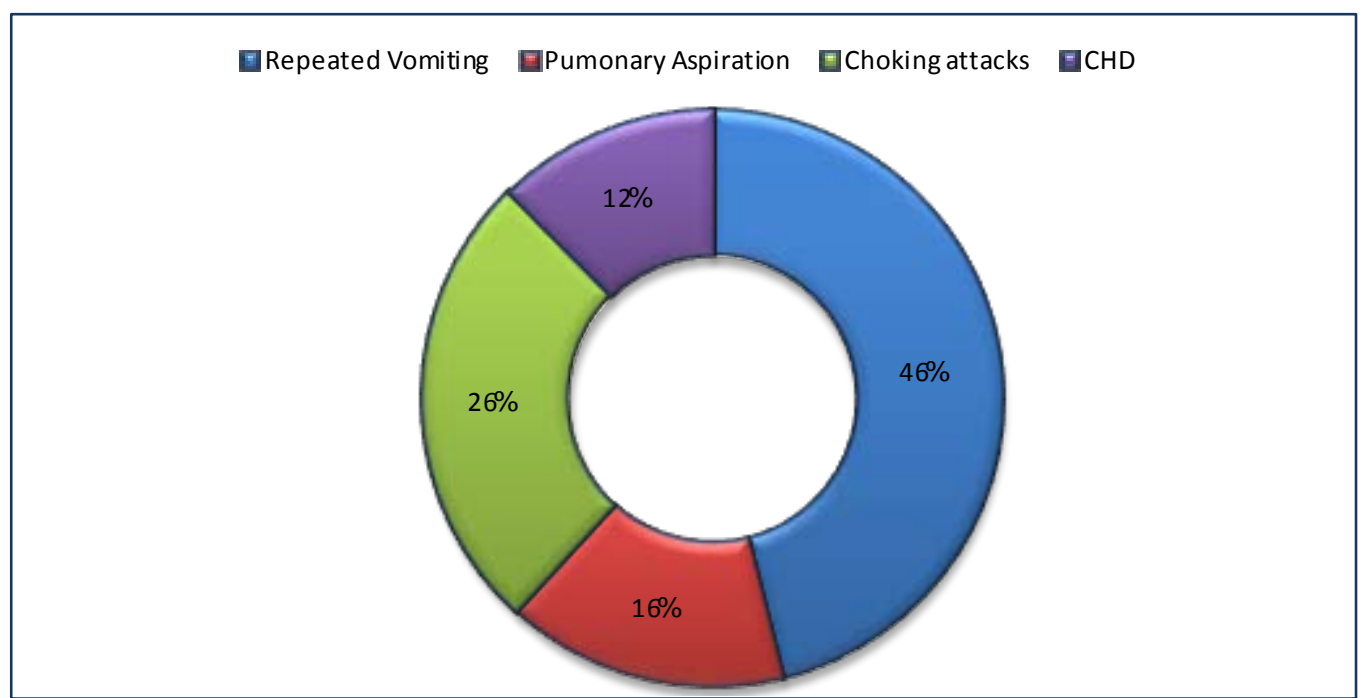

Figure 5. Shows frequency distribution of reason of examination in relation with milk scan study and finding. 


\subsection{Frequency Distribution of Incidence of Pulmonary Aspiration, Gastric Emptying, with Regard to Milk Scan Study}

Figure 6 shows us a group of 68 cases were monitoring regarding pulmonary aspiration and gastric emptying. $1.5 \%$ of 68 cases were with positive finding of pulmonary aspiration, while gastric emptying as shown in the figure represents with $73.5 \%$ positive finding of the overall cases.

\subsection{Effect of Using Nasogastric Tube "NGT" in Milk Scan Study Finding}

Figure 7(a) \& Figure 7(b) show us a group of 68 patient who prepared to be examined using NGT, and the result was 49 patients with positive finding and only 13 patients with negative finding that means with the use of NGT the scan is more useful and the degree of positive finding were $79 \%$ of overall 68 cases. NGT was found to be proportional to both volume and duration of reflux. Similarly, increasing the radioisotope concentration of reflux or absolute gamma camera sensitivity produced a proportional increase in extension of the nasogastric tube.

\subsection{Distributions of Location and Degrees of GER among Subject Group with Milk Scan Study}

Figure 8 shows the different location and degrees of reflux are found in patients with GER $56.20 \%$ of overall cases. Most of GER patients (50\%) have abnormal tracer activity in the mid of esophagus, while $28 \%$ of patients who have abnormal reflux were observed in the upper of esophagus, only $22 \%$ have abnormal pattern in the lower of esophagus.

\section{Discussion}

Radionuclide studies of esophageal transit have been in infants and small children. Cooperation is not possible in children; however, it can record the transit of patient with inject the milk by NGT in supine position with posterior and interior imaging. In some imaging centers, it is performed with the camera in the anterior position only.

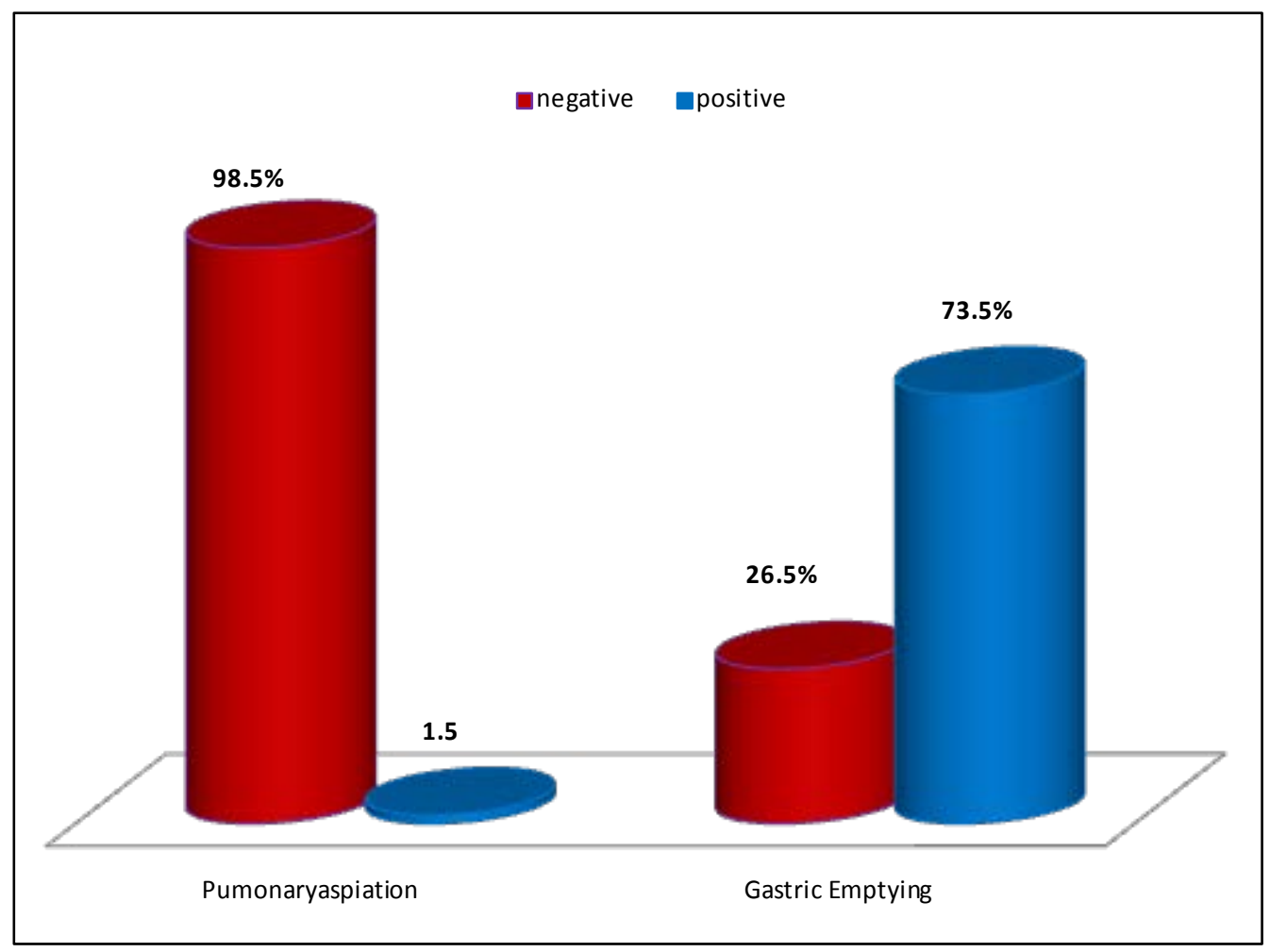

Figure 6. The figure shows frequency distribution of incidence of pulmonary aspiration, gastric emptying and GER regard to milk scan study. 


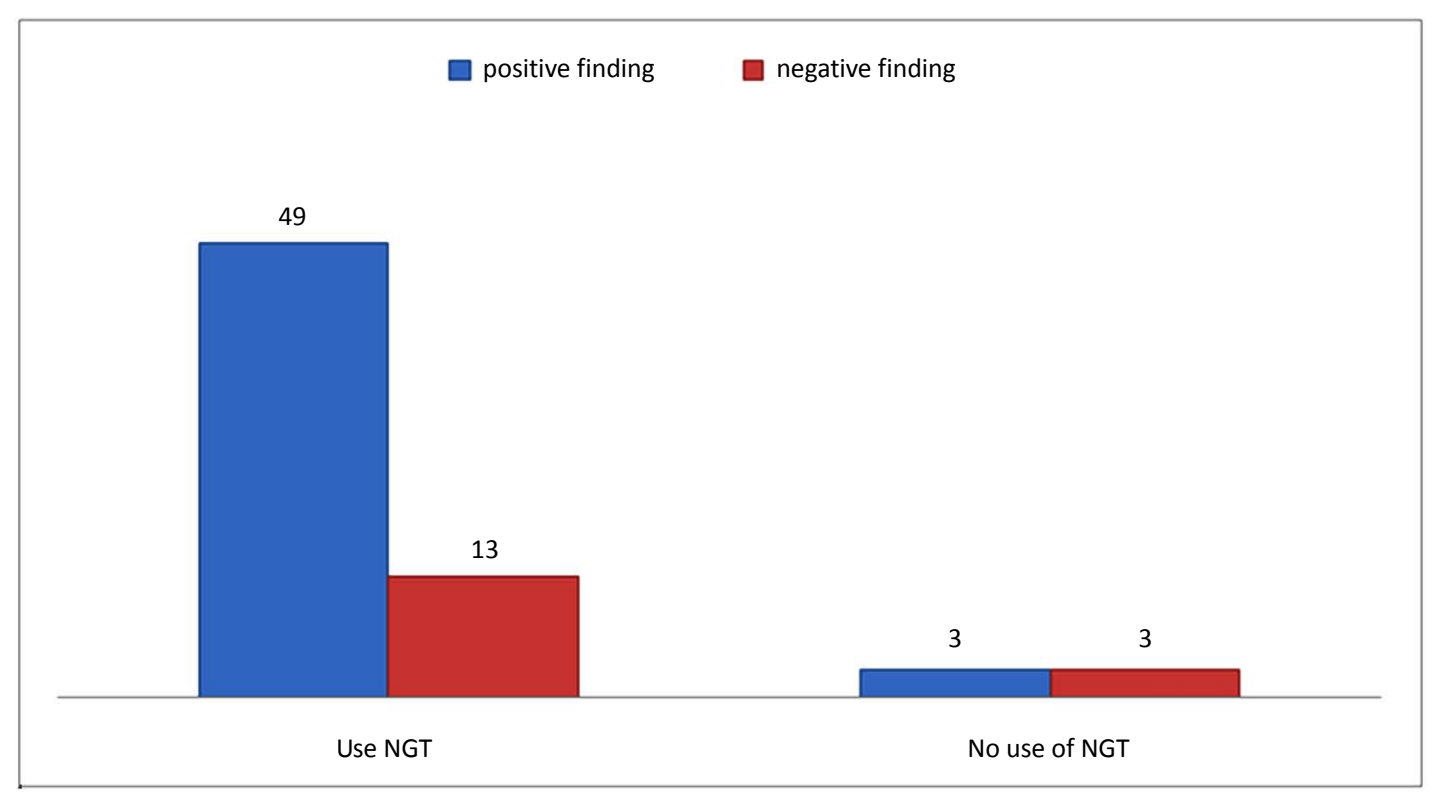

(a)

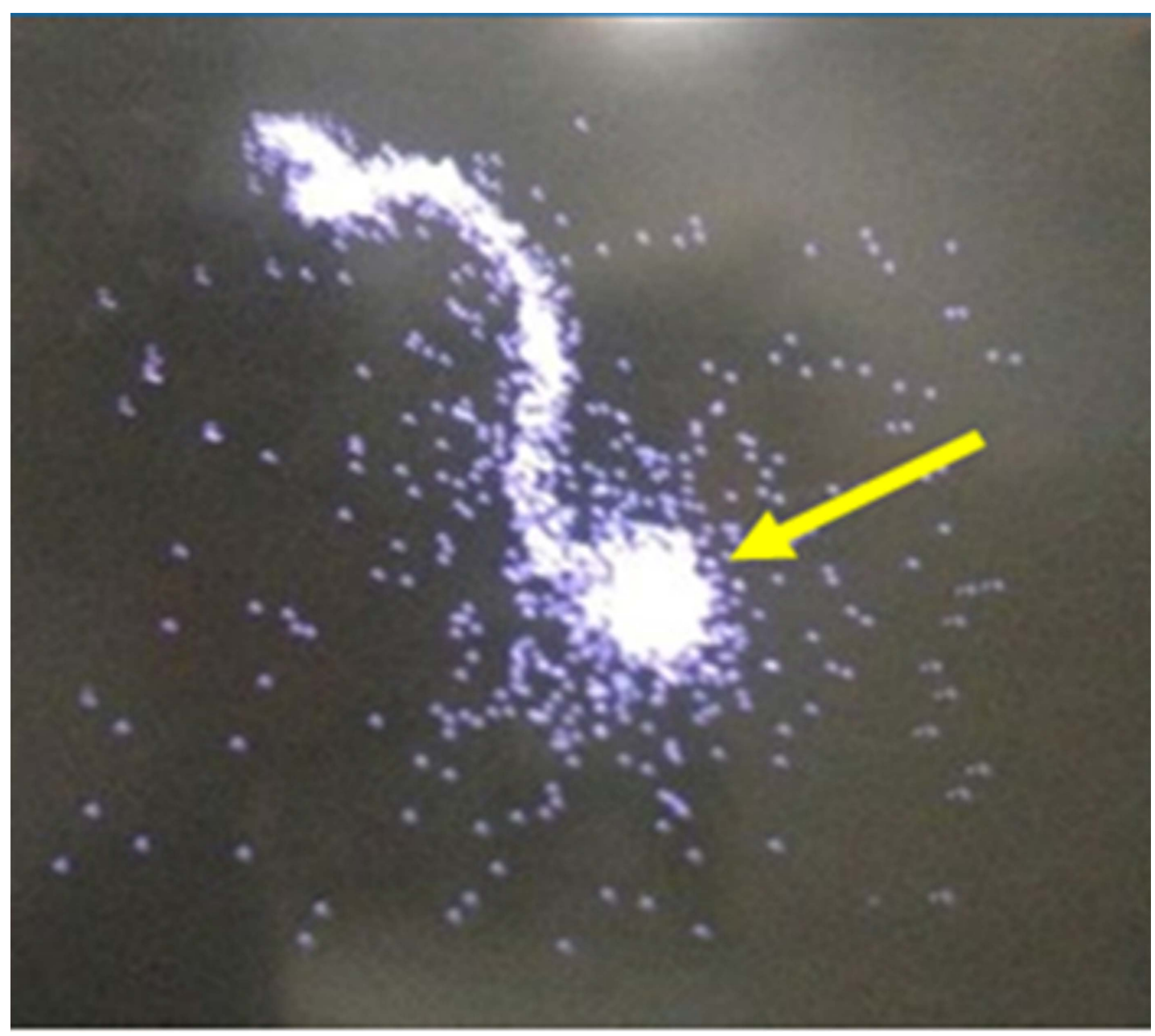

(b)

Figure 7. (a) \& (b) show effect of using nasogastric tube "NGT" in milk scan study finding. 


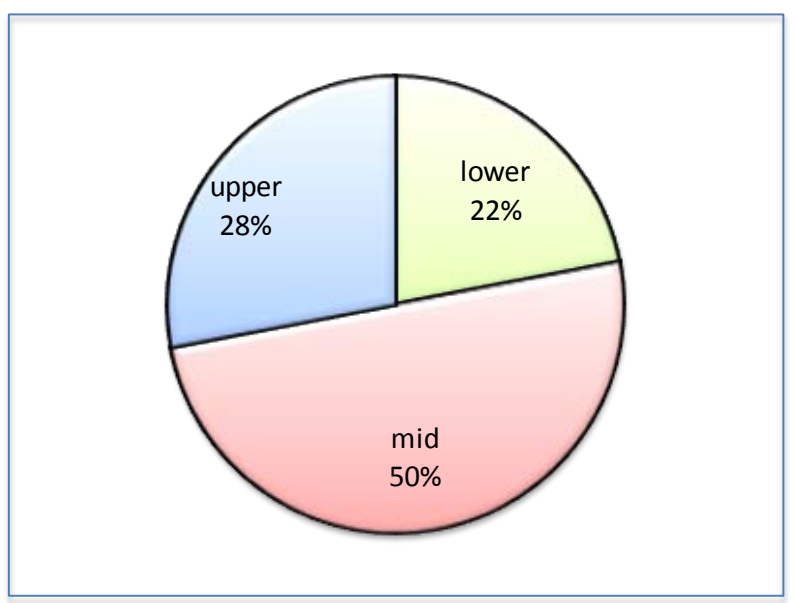

Figure 8. The figure shows the distribution of the whole sample according to reflux finding.

Anterior imaging has specific advantages. With anterior imaging, patient to-collimator distance can be achieved as close as possible. In posterior imaging, counts originating from GER can be attenuated by the superimposed spine and the imaging table. Despite these considerations, we feel that posterior imaging is more practical and does not sacrifice, to any significant extent, the ability to detect reflux and aspiration [2].

We found in our study posterior imaging with the camera head positioned under the imaging table, there is an unobstructed space over the imaging bed allowing easy communication with the children and access to caregivers. The children are more relaxed and we can perform the dynamic study over 60 minutes. A milk scan that can be done in our project to measure reflux into the esophagus in supine position was because the supine position was found to be more sensitive, accurate and comfortable more than other positions. This was mentioned by Piepsz A and Georges B who stated that, "The supine position was found to be more sensitive than the prone, left lateral, and 30-degree right posterior oblique positions for detection of GER” [3].

This is not a comparative study, but Gastro-esophageal reflux scintigraphy is a sensitive, noninvasive, physiologic, and direct technique to demonstrate the presence of GER. It is easy to perform, is well tolerated, and requires minimum patient cooperation. It also entails a relatively low radiation burden. According to most studies, the sensitivity of gastro-esophageal scintigraphy for detection of GER in comparison to $\mathrm{pH}$ monitoring ranges from $60 \%$ to $90 \%$ [4], specificity is over $90 \%$ [5] [6].

In a few studies that performed simultaneous esophageal $\mathrm{pH}$ monitoring and scintigraphy for 1 to 2 hours, no correlation was found between the total number of reflux episodes detected by scintigraphy and $\mathrm{pH}$ monitoring. Scintigraphy, however, detected more reflux episodes than $\mathrm{pH}$ monitoring [7].

Gastro-esophageal reflux disease (GERD) occurs when episodes of GER produce symptoms and complications. We found in our study, in regard GER incidence according to repeated vomiting, pulmonary aspiration, choking attacks, and CHD symptoms, the studies show that repeated vomiting is the highest frequency reason for milk scan study with $46 \%$ of the overall cases, although the positive finding of GER were $51 \%$ for repeated vomiting, so repeated vomiting represents the most frequent symptom for GER. Also age group of 0 - 6 months old represents the highest frequency for milk scan study with $56.20 \%$ of overall cases positive finding for GER. While the request for the scan decreases with the increase of age finding for age group 7 - $12 \mathrm{M}, 13$ - $18 \mathrm{M}, 19$ $24 \mathrm{M}, 25$ - $46 \mathrm{M}$.

This was proved by Nelson SP, Chen EH and EH, Syniar GM, who stated "The main GER-related symptom in infants is recurrent vomiting. It occurs in $50 \%$ of infants during the first 3 months of life and in $67 \%$ of 4-month-old infants. Vomiting resolves spontaneously in the majority of infants and is encountered in only $5 \%$ of infants at the age of 10 to 12 months" [8].

\section{Conclusion}

Gastro-esophageal reflux scintigraphy is a sensitive, noninvasive, physiologic, and direct technique to establish the presence of GER. The finding of milk scan study is that it is not affected by gender. The most frequent age 
for milk scan study is 0 - 6 months old. The commonest reason of examination for milk scan was linked with patients who suffer repeated vomiting. The use of NGT in milk scan study is more useful. It also entails a relatively low radiation burden. The time activities curves permit qualitative and quantitative assessment of the bolus transit.

\section{Recommendations}

Infants especially with age group of 0 - 6 months old are strongly recommended to milk scan rather than fluoroscopy to avoid unnecessary dose to the patients. Infants who suffering repeated vomiting is kindly recommended to have milk scan study. Further studies needed in comparison with fluoroscopy to find out the exact radiation dose that may harm the patients and how much it is clinically useful to replace fluoroscopy exam by milk scan.

\section{References}

[1] Thrall, J.H. and Ziessman, H.A. (2001) Nuclear Medicine: The Requisites. 2nd Edition, Mosby, St. Louis, $233-237$.

[2] Blumhagen, J.D., Rudd, T.G. and Christie, D.L. (1980) Gastroesophageal Reflux in Children: Radionuclide Gastroesophagography. American Journal of Roentgenology, 135, 1001-1004. http://dx.doi.org/10.2214/ajr.135.5.1001

[3] Piepsz, A., Georges, B., Rodesch, P. and Cadranel, S. (1982) Gastroesophageal scintiscanning in children. Journal of Nuclear Medicine, 23, 631-632.

[4] Arasu, T.S., Wyllie, R., Fitzgerald, J.F., Franken, E.A., Siddiqui, A.R., Lehman, G.A., et al. (1980) Gastroesophageal Reflux in Infants and Children Comparative Accuracy of Diagnostic Methods. The Journal of Pediatrics, 96, 798-803. http://dx.doi.org/10.1016/S0022-3476(80)80545-2

[5] Seibert, J.J., Byrne, W.J., Euler, A.R., Latture, T., Leach, M. and Campbell, M. (1983) Gastroesophageal Reflux-the Acid Test: Scintigraphy or the $\mathrm{pH}$ Probe? American Journal of Roentgenology, 140, 1087-1090. http://dx.doi.org/10.2214/ajr.140.6.1087

[6] Patwari, A.K., Bajaj, P., Kashyp, R, Anand, V.K., Gangil, A., Jain, A., et al. (2002) Diagnostic Modalities for Gastroesophageal Reflux. The Indian Journal of Pediatrics, 69, 133-136. http://dx.doi.org/10.1007/BF02859372

[7] Tolia, V., Kuhns, L. and Kauffman, R.E. (1993) Comparison of Simultaneous Esophageal pH Monitoring and Scintigraphy in Infants with Gastroesophageal Reflux. The American Journal of Gastroenterology, 88, 661-664.

[8] Nelson, S.P., Chen, E.H., Syniar, G.M. and Christoffel, K.K. (1997) Prevalence of Symptoms of Gastroesophageal Reflux during Infancy: A Pediatric Practice Based Survey. Archives of Pediatrics and Adolescent Medicine, 151, $569-572$. http://dx.doi.org/10.1001/archpedi.1997.02170430035007 
Scientific Research Publishing (SCIRP) is one of the largest Open Access journal publishers. It is currently publishing more than 200 open access, online, peer-reviewed journals covering a wide range of academic disciplines. SCIRP serves the worldwide academic communities and contributes to the progress and application of science with its publication.

Other selected journals from SCIRP are listed as below. Submit your manuscript to us via either submit@scirp.org or Online Submission Portal.
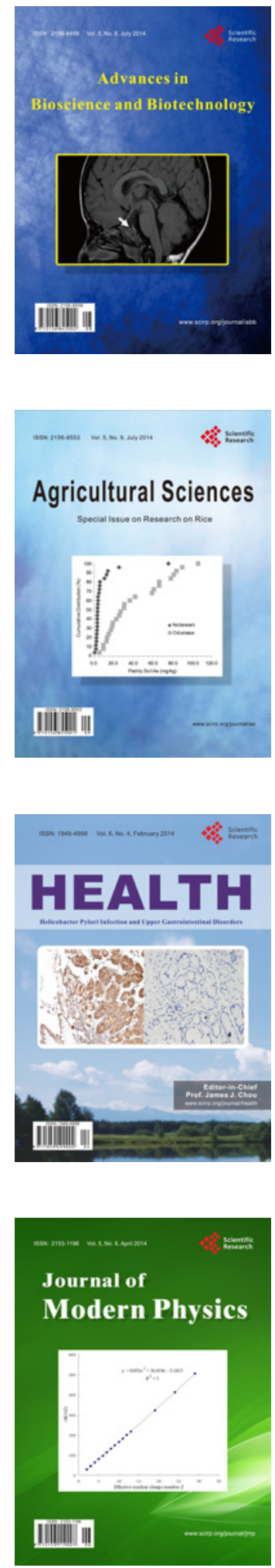
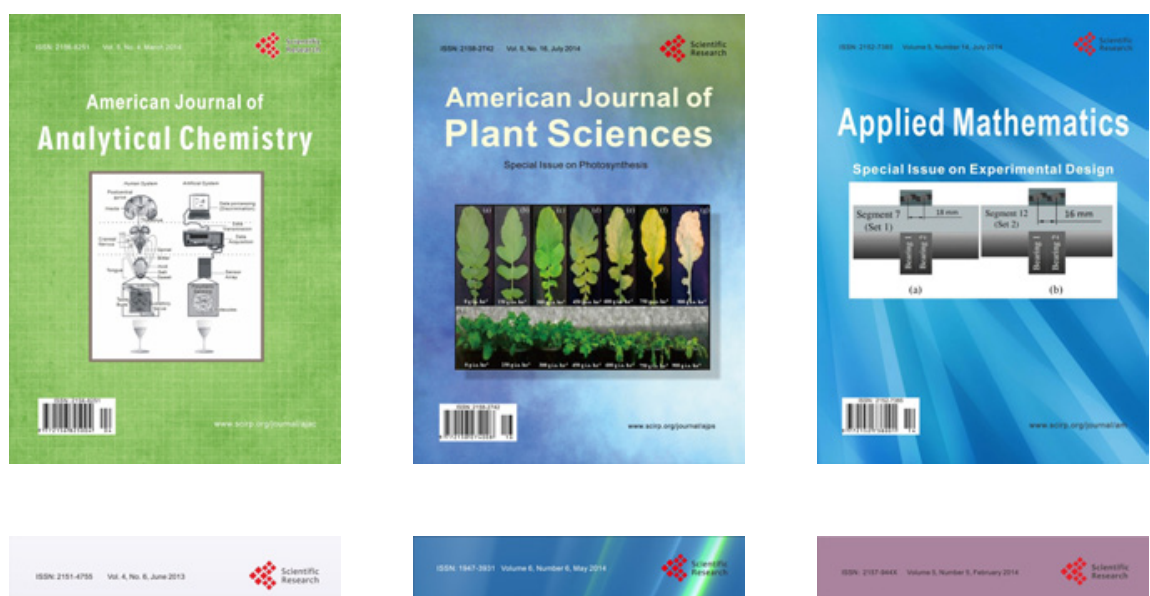

Creative Education
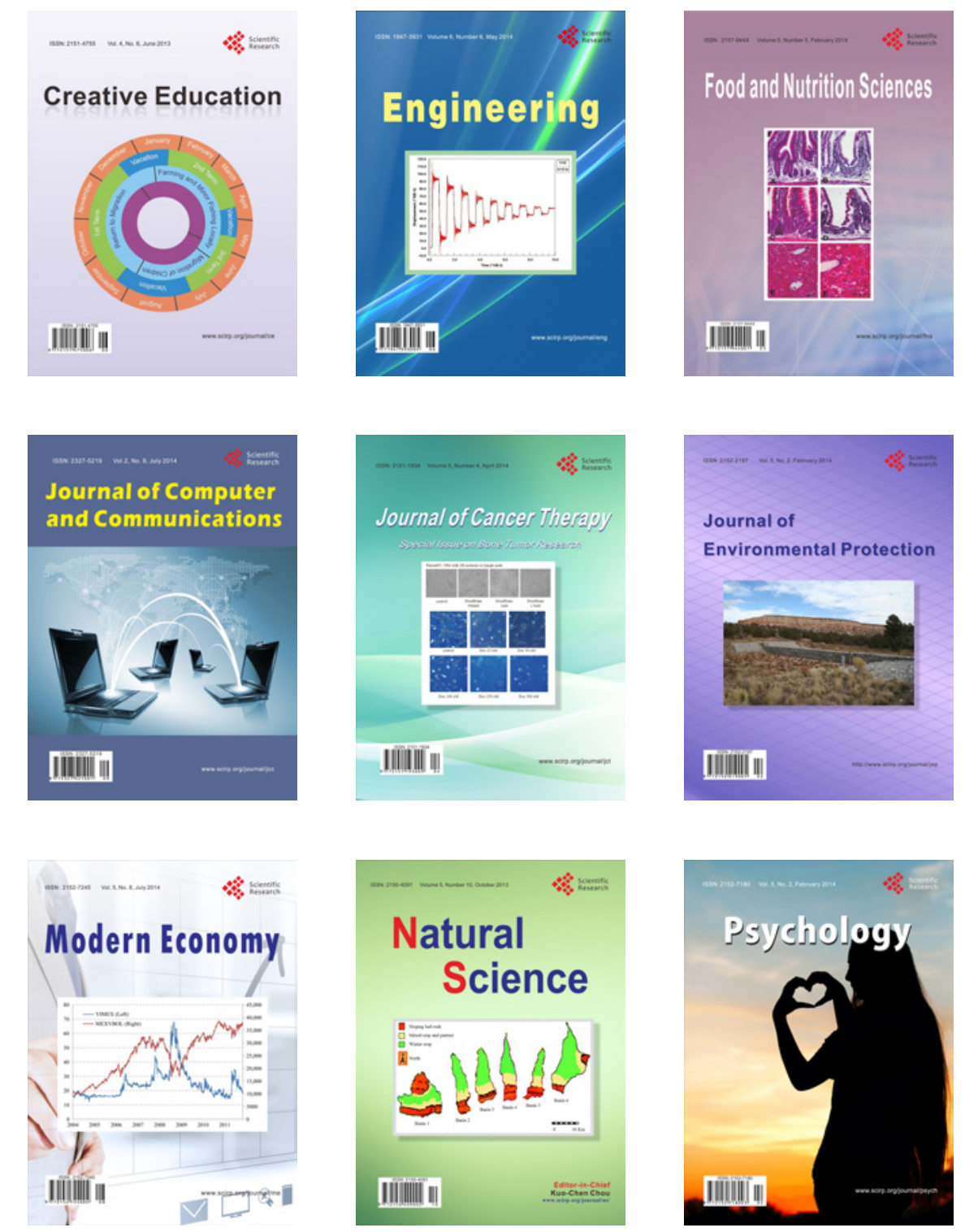